\title{
Hypotheses and facts
}

\section{Hilary Koprowski}

Thomas Fefferson University, 1020 Locust Street, Suite M85, Philadelphia, PA 19107, USA

\begin{abstract}
The book, The river, is based on assumptions and not facts. Oral polio vaccine was produced entirely in rhesus monkey kidney cell cultures. Allegations that it was produced in chimpanzee kidneys at the Wistar Institute in Philadelphia or, alternatively, that the vaccine was made in the then Belgian Congo in chimpanzee kidney has no basis in fact. As the only witness to the historical events leading to the development of oral polio vaccine, I have demonstrated in this paper the truthful facts excluding any link between oral polio vaccine and human immunodeficiency virus.
\end{abstract}

Keywords: AIDS; CHAT; chimpanzee; Congo; oral polio vaccine; The river

I hope you will be able to understand what I have to say, as some people have had difficulty with my PolishEnglish. So, in which language should I give my talk? When I asked one of my friends, a scientist whose mother tongue is also not English, he replied 'in the language of science'. And when asked, 'what is the language of science?' he replied 'broken English, spoken slowly'.

According to Popper in The logic of scientific discovery (Popper 1992) rational theory is constructed by putting forth a hypothesis and then seeking evidence that disproves rather than supports that hypothesis. On the other hand, Francis Bacon in New organon (Wormald 1993) argued that the first step before you construct a theory or hypothesis is the assembly of as much factual information with as few preconceptions as possible. In Brian Martin's words, 'compatibility with facts is one of the important factors required to judge a scientific theory' (Martin 1998). The author of The river (Hooper 1999), on the other hand, followed Popper in constructing a hypothesis from a theory without, however, seeking evidence to disprove the hypothesis as advised by Popper. Instead he turned to Bacon to assemble some factual information to support a pre-existing hypothesis. This was not what Bacon advised. Moreover, Bacon stressed to 'assemble as few preconceptions as possible', whereas The river has operated with preconceptions without much attention to contradictory data. Bolstered by the media, the author has succeeded in an amazing way and the media have called on scientists to accumulate facts to support the preconceived ideas of Mr Hooper.

Plotkin (this issue) has given the true history of the CHAT type 1 polio vaccine that I developed and I will not enter into the details again. However, it is worthwhile reminding you of the prevailing ideas at the time concerning attenuation. Lacking the molecular methods available today to induce and detect mutations, we had to proceed cautiously by trial and error. We carefully watched the effects of clonal selection, in the old sense of the word, and the effects of environmental conditions such as temperature and the substrate in which the strain was grown, be it of avian or mammalian origin. Thus, a switch to a new substrate, such as chimpanzee kidney, would have been closely studied in the laboratory and in animals, and would certainly not have been a whimsical decision.

The possibility that CHAT was contaminated with an as yet unidentified virus, as claimed by Sabin, deserves comment. With our agreement Sabin and I were to interchange strains of polio used for vaccine production. He received my strain and claimed that an unidentified, nonpoliomyelitis cytopathogenic virus (for epithelial monkey cells unlike human immunodeficiency virus (HIV) or simian immunodeficiency virus (SIV)) was found in my preparation (Sabin 1959). Since Sven Gard, an eminent Swedish virologist working in my laboratory, found no extraneous viruses in the samples sent to Sabin, it is possible that the samples were contaminated in Sabin's laboratory during their passage of the virus in the SV40 infected monkey kidney tissue (Koprowski 1959). But SIV is not SV40. Evidence of SIV growth in monkey epithelial kidney cells is equivocal but reflects very low levels of replication. Indeed, Narayan (personal communication) failed to demonstrate any evidence of infectious virus in epithelial cell cultures derived from the kidneys of monkeys known to be infected with SIV. It is unlikely that trypsinized chimp epithelial kidney cells handled in the usual way in culture could have contained infectious retrovirus.

The central point of his speculations is that infected chimp kidneys were sent from Camp Lindi near Stanleyville to Philadelphia or Brussels. We never used chimp kidneys. No evidence exists for that assertion, nor is there a single affirmative firsthand witness. In The river (Hooper 1999), the author cites five scientists who believe that chimpanzee kidneys were used to make the vaccine. Two are Belgian veterinarians (mentioned above), who reported being told by colleagues that chimp kidneys were sent to the United States and to Belgium for tissue culture. Neither veterinarian had any knowledge as to exactly where the kidneys went and, in fact, both now deny they said that. The third scientist was from Lederle, who could have had no personal knowledge of what went on at the Wistar Institute. The fourth and fifth scientists are quoted anonymously. Neither claimed any first-hand knowledge of what had been done or not done with the Koprowski vaccines. 
Is this evidence of anything? Permit me to correct some of the Congo chronology inasmuch as I was there in 1957 and the author was not. For example, he charts the travels of the late Tom Norton and myself throughout the Congo without ever checking with us. According to The river, we were supposed to have visited an individual named Jezierski who, according to The river, attenuated poliovirus himself in his laboratory in Gabu Nioka and we were supposed to have visited his laboratory in 1957. We did not visit his laboratory. The truth is that Jezierski spent three days with us as a guide to the pygmy camp in the Epulu Forest, and travelling an additional 500 miles through the jungle in a single day to reach his laboratory would have been a major accomplishment.

Among other inaccuracies is the belief that I went to Camp Lindi in the Congo in 1955. I was stranded in Léopoldville for two days in 1955 since my plane from South Africa suffered a mechanical breakdown. But my real visits to Camp Lindi took place only twice, in February and October of 1957, which would have been a bit late for the production of vaccine to be distributed in February 1957. A mistake appears to have been made in the translation of a sentence from a Polish biography of myself (Tuszynska 1996), which says: 'In 1955 arrangements were made for travel to the Belgian Congo'. Faulty translation has changed this to: 'Koprowski claims that he made his first trip to Stanleyville and the site of Lindi Camp in 1955' (not 1957). This appears to have stimulated wild speculation that I started acquiring chimp kidney cultures in 1955.

Another opinion that I cannot agree with is that CHAT was an experimental vaccine and that its use was unjustified in the Congo. CHAT was no more experimental than Sabin's Lsc-2ab type 1 strain, used in the former Soviet Union under the same open protocol as we used in the Congo, that is to say, without placebo controls and with only general rather than detailed surveillance of the aftermath. I am sure that the late Sabin and I would both accept criticism for lacking the kind of safety controls in 1957 that would be considered appropriate today, but no experimentalist in that era conducted clinical trials using today's rules. Above all, polio was considered an acquired immune deficiency syndrome (AIDS)-like crisis at that time and aggressive attempts at prevention were felt to be mandatory. In fact, as verified by correspondence of the time, I tried to convince the Belgian authorities to accept a placebo-controlled trial, but they refused on the grounds that it might delay implementation of the vaccination campaign. Indeed, the trials in the Congo were organized with the full collaboration of the Belgian authorities and requested by them, two facts evidently being lost to history. After the initial trials in the Ruzizi Valley and in Léopoldville, and the collection of data on serosusceptibility, the medical authorities decided (as reported in the Le Courier d'Afrique 1959) to vaccinate all European children starting school in the Congo with oral polio vaccine. There was a plan to extend the vaccination to the entire population of the Congo, which never took place because of the political events toward the end of 1959.

The author attacks the polio vaccine trials by claiming that most of the vaccinees were already immune to polio.
In the Ruzizi Valley campaign, 20 000-30 000 recipients were seronegative, but when we focused on children less than five years old, we were vaccinating a population in which $55-65 \%$ were susceptible to polio. Were we being unethical and asking the Congolese to take risks not taken by others? Hardly. During the same period that we were using the vaccine in the Ruzizi Valley and Léopoldville, trials were being done in Philadelphia (Pagano et al. 1960), New Jersey (Plotkin et al. 1960), Switzerland (Buser \& Schar 1961) and Poland (Przesmycki et al. 1959). In fact, Americans and Europeans and my own children who were vaccinated before were assuming the same risks as the Congolese. My children have not yet instituted litigation.

Finally, and most importantly, I would like to turn to a more sombre consequence of unfounded speculations. The year 2000 included the anniversary of the date 27 February 1950, when I fed a child with the first oral polio vaccine (The Nation 1999). The year 2000 was supposed to be the year when polio was completely eradicated from this globe. In all of the reviews of The river that I have read, not one has mentioned this fact. Apparently, even for reviewers with a scientific background, The river's hypothesis is a sensation while the eradication of polio is just 'old hat'. According to the World Health Organization, it is in India and Africa where vaccination with oral polio vaccine must be completed in order to declare the world polio-free. But then enter The river with its tale that vaccination against polio may bring the deadly gift of another disease such as AIDS.

And what is the response in Africa? This news has spread in Africa, and the Catholic Church in Kenya, despite the objection of medical authorities, advised mothers not to take their children for polio vaccination as it was contaminated with HIV (The Nation 1999).

So one of the greatest efforts by numerous institutions throughout the world to completely eradicate a deadly disease may now be compromised because of The river.

Nine years ago, a writer named Tom Curtis wrote a story that appeared in Rolling Stone Magazine, in which he postulated that the mass trials of my polio vaccine in the Belgian Congo in the late 1950s were the possible cause of the AIDS epidemic (Curtis 1992). Curtis interviewed me under the guise that he was writing an article about the search for a polio vaccine. Instead he used it as a vehicle to introduce a wild theory that my possible use of green monkey kidney, which might have harboured SIV, was used for the production of the oral polio vaccine.

Curtis ignored the fact that even if African green monkey kidneys were used, and even if they contained SIV, and even if the SIV survived the vaccine manufacture process and even if the SIV virus could be transmitted to humans through the oral route, the genetic differences between African green monkey SIV (SIVagm) and HIV are so great that it would take thousands of years for SIVagm to mutate into HIV. His article was lacking in credibility because there were no facts to support his speculations.

The seed was planted. A short time later a reporter from the Associated Press, following up on Curtis's unfounded allegations, wrote a story published around the world that a monkey virus that causes simian AIDS was found in a Koprowski vaccine. The vaccine, in which a 
simian retrovirus D was reportedly found, was, in fact, a sample of a Salk vaccine, not a Koprowski vaccine. The sample of Salk vaccine was also tested for SIV and HIV. No SIV or HIV was found, yet the reporter failed to mention this in his article. Nor did he mention that there is absolutely no connection between retrovirus D and HIV.

Again, Koprowski is held out before the world as the 'father of AIDS'.

In both cases, the facts were misrepresented and scientific method was ignored. The published misconceptions have apparently provided the foundation for more speculation, misconceptions and factual errors, which again paint Koprowski as the creator of a vaccine that gave the world AIDS and killed millions of people. But this is a dangerous fantasy! I find it most disturbing that stories about my polio vaccine may threaten the very elimination of this terrible disease. I hope that by the end of this conference I will be acknowledged for my achievements for developing the oral polio vaccine, which has saved millions of lives and which has absolutely nothing to do with the dissemination of AIDS.

I would like to thank Mr Geoffrey Johnson for his help concerning the last part of my talk.

\section{REFERENCES}

Buser, F. \& Schar, M. 1961 Poliomyelitis vaccination with live poliovirus. Am. F. Dis. Child. 101, 60-66.

Curtis, T. 1992 The origin of AIDS: a startling new theory attempts to answer the question: 'Was it an act of God, or an act of man?'. Rolling Stone 626, 54-60, 106-108.

Hooper, E. 1999 The river: a journey back to the source of HIV and AIDS. Harmondsworth, UK: Little, Brown \& Co.
Koprowski, H. 1959 Live poliomyelitis vaccine. Br. Med. 7. 5133, $1349-1350$.

Koprowski, H., Jervis, G. A. \& Norton, T. W. 1952 Immune responses in human volunteers upon oral administration of a rodent-adapted strain of poliomyelitis virus. Am. F. Hyg. 55, 108-126.

Le Courier d'Afrique Lundi, 4 March 1959, p. 6.

Martin, B. 1998 Political refutation of a scientific theory: the case of polio vaccines and the origin of AIDS. Hlth Care Anal. 6, 175-179.

Pagano, J. S., Plotkin, S. A., Janowsky, C. C., Richardson, S. M. \& Koprowski, H. 1960 Routine immunization with orally administered attenuated poliovirus: a study of 850 children in an American city. F. Am. Med. Ass. 173, 18831889.

Plotkin, S. A., Koprowski, H., Richardson, S. M. \& Stokes, J. 1960 Vaccination of families against poliomyelitis by feeding and by contact spread of living attenuated virus including studies of virus properties after human intestinal passage. Acta Paedia 49, 551-571.

Popper, K. R. 1992 Logic of scientific discovery. London: Routledge. Przesmycki, F., Dobrowolska, H., Olakowski, T., Stanczyk, R. \& Naruszewicz, D. 1959 Report on field trials with live attenuated poliomyelitis vaccine in Poland. First Int. Conf. on Live Poliovirus Vaccines, Washington, DC, 22-26 June 1959. Pan American Sanitary Bureau publication no. 44, pp. 497-507. Washington, DC: Pan American Sanitary Bureau.

Sabin, A. 1959 Present position of immunization against poliomyelitis with live virus vaccines. Brit. Med. F. i, 663-680.

The Nation, 'Catholic stand on disease criticised', 26 November 1999. National Newspapers, Ltd.

Tuszynska, A. 1996 Hilary Koprowski-Wygrac Kazdy Dzien (translation: Hilary Koprowski-To win every day). Warsaw: published under the auspices of the Kosciuszko Foundation, Diana Co.

Wormald, B. H. G. 1993 Francis Bacon: history, politics and science: 1561-1626. Cambridge University Press. 